\title{
Language learning and teaching
}

\section{THEORY AND PRINCIPLES See also abstracts 79-79, $-83,-89$}

79-44 Arrouays, Michel and Moerdijk, Donald. Place, rôle et pratique de l'enseignement des langues: pour une nouvelle approche. [The place, role and practice of language teaching: towards a new approach.] Langues Modernes (Paris), 72, 2 (1978), 143-55.

Traditional language teaching abounds in proscriptions but is silent about its aims. Teachers toy with techniques while content remains unchanged. [Review of the cultural content, the status and power wielded by the speakers of nonnative European languages from Latin to the present day.] To teach adequately implies providing the learner with an additional means of structuring the space-time of his own life. The learner deserves more attention but psycholinguistics has low research status. A child re-inforces its self-identity in the process of learning its mother-tongue; a foreign language threatens this establishment of personality. A learner must overcome the resistance put up by his unconscious. [Suggested typology of exercises: (1) to develop language capacity; (2) to acquire new items; (3) to put language systems in perspective. Tests of factual knowledge; role-playing; reasoning about language systems.] Any progress must involve the majority of teachers.

79-45 Sampson, Gloria Paulik. A model for second-language learning. Canadian Modem Language Review (Toronto), 34, 3 (1978), 442-54.

Three models of language learning are compared: (1) the creative construction hypothesis, (2) the inter-language hypothesis and (3) the approximative systems model. The latter, which incorporates both functional and linguistic analysis approaches to language learning, not only describes second-language learning data, but also, in contrast to the other two models, explains why learners progress as they do.

79-46 Savey, D. Finalités et objectifs de l'enseignement des langues vivantes. [Aims and objectives of modern-language teaching.] Langues Modemes (Paris), 71, 5/6 (1977), 481-94.

The objectives of modern-language teaching cannot be dissociated from the concepts underlying educational policy and the aims and objectives set for education as a whole: should students be selected and trained to fill an existing niche in society or should education be student-centred and directed towards the development of individual potential? 
Modern language teaching should be based on students' real interests rather than on what is supposed to interest them. Students should to work together in groups and should be encouraged to discover and work things out for themselves. Such an approach has proved highly successful where it has been tried. [Implications for teacher training are discussed.]

79-47 Stern, H. H. Language research and the classroom practitioner. Canadian Moderm Language Review (Toronto), 34, 4 (1978), 680-94.

A discussion of the place and function of research in language teaching. Research has increased considerably in the last 15 to 20 years. It may provide information or explanations, or clarify concepts or theories and influence attitudes, even if it is not detectable in classroom procedures. It can also assist in policy decisions by putting the various possibilities before the decision-maker. Four models of the relationship between research and practice are discussed: the application model, the separation or 'hands-off' model, the resource model and the common-ground or convergence model. It is the latter which should guide policy on research; the ideal form of interaction between researchers and practitioners is one in which they are on equal terms and work together. The types of research needed now are: (1) basic research on the processes of language teaching and learning. (2) Descriptive and analytical investigations of individual languages, societies and cultures. (3) Research related to policy issues. (4) Evaluative research, monitoring the development of existing programmes or activities.

\section{PSYCHOLOGY OF LEARNING}

79-48 Frith, May B. Second language learning: a study of the form and function of the progressive at two stages of developing interlanguages. Interlanguage Studies Bulletin (Utrecht), 3, 1 (1978), 102-17.

This paper reports on a cross-linguistic study of the acquisition of English by four subjects, six months and nine months after their first introduction to English. The study was designed to test the 'approximative system ' hypothesis put forward by Nemser (1969) which states that the learner of a second language acquires a series of transitional grammars each of which more closely approximates the target language (TL). An important implication of this assumption is that the learner is seen as an hypothesis-tester working creatively with the TL system rather than one who merely imitates the structures of the input data.

Spontaneous oral production $\mathrm{T} 1$ and $\mathrm{T} 2$ data were collected and analysed in order to describe and explain the changes in the subjects' interlanguages 
between the two stages. Five grammatical categories were examined: the progressive, the third person singular, the simple past tense, articles and prepositions. Only the analysis of the progressive is dealt with in this paper.

While the results offer insufficient evidence to support the hypothesis of a different stage in the grammar of each subject in all the selected grammatical categories, they show very clearly that each learner, is simplifying the TL by the omission of functionally redundant morphemes, was working creatively with the system.

79-49 Greenbaum, Sidney. Judgments of syntactic acceptabiity and frequency. Studia Linguistica (Lund, Sweden), 31, 2 (1977), 83-105.

The three experiments reported here investigated $(a)$ the feasibility of using frequency judgments (i.e. judgments as the to relative frequency of use of various constructions) by native speakers for the syntactic description of English, (b) the possibility of a relationship between frequency and acceptability judgments, and $(c)$ some linguistic variables that influence changes in perceived frequencies and in acceptability. [Method; tables of results.] It was found that subjects can be consistent in their syntactic judgments of both frequency and acceptability; there seems to be an association between frequency and acceptability judgments. Although the reliability of a single subject is predictably low, the reliability of the group is comparatively high. [For an analysis of the linguistic aspects of the results, the 100 sentences were divided into eight groups each of which dealt with a particular type of syntactic variation, e.g. active/passive, may/might, perfect/past.]

79-50 Meara, Paul. Schizophrenic symptoms in foreign-language learners. UEA Papers in Linguistics (Norwich), 7 (1978), 22-47.

This paper outlines the main characteristics of schizophrenic language behaviour in order to highlight various similarities between it and the behaviour of foreign-language learners. The four main areas discussed are $(a)$ low type-token ratios, $(b)$ unpredictability of speech, (c) few sequential redundancies, and $(d)$ abnormal word-association patterns. It is concluded that people working with bilingual schizophrenics must take great care in using tests to diagnose them, and these tests should be based on the patients' native languages, rather than their weaker languages. More dialogue is needed between clinical linguists and those concerned with language teaching. Two neglected areas are the biological bases of foreign-language behaviour and the relationship between personality and language learning. 
79-51 Pitts, Ruth Ann. The effects of exclusively French-language schooling on self-esteem in Québec. Canadian Modern Language Review (Toronto), 34, 3 (1978), 372-80.

A random sample survey of 300 French Canadians in Québec investigated the relationship between self-esteem and schooling entirely in French or partly in English, and the mechanisms associated with high self-esteem. Results showed that French Canadians who attended French schools exclusively have higher self-esteem not because they set their sights lower (as the researchers hypothesised), but because they are more ambitious, the French Canadian élite having a strong belief in success and North American values. Schooling exclusively in French also leads to high self-esteem because the ethnic group is valued, despite lower positions in the occupational structure.

79-52 Treisman, Michel. Space or lexicon? The word frequency effect and the error response frequency effect. Journal of Verbal Learning and Verbal Behavior (New York), 17, 1 (1978), 37-59.

Theories of the recognition of complex stimuli, and especially words, are briefly considered. Such theories may assume that the perceptual system has access to a store of representations of potential stimuli. The assumptions which may be made about such a store are discussed and distinctions are drawn between three types of organisation: as a collection, as a tree or lexicon, and as a space. These distinctions relate essentially to the mode of access to the contents of the store, as it affects the nature of the samples drawn from the store when sampling is supposed to occur. Four predictions are derived from the concept of an acoustic space, in the sense defined, and which would not hold of a store organised as a tree or collection. They state that the relation between frequency of occurrence in the language and frequency of occurrence as an error will be weak; this relation will decrease as the discriminability of stimuli increases; if words which are very infrequent as errors are contrasted with the remainder of the vocabulary, which are more frequent as errors, the former may actually be more likely to be recognised correctly than the latter; and this inversion of the classical frequency effect will become more pronounced as the discriminability of the stimuli increases. Evidence supporting all four predictions is reported.

79-53 Wode, Henning. Free vs. bound forms in three types of language acquisition. Interlanguage Studies Bulletin (Utrecht), 3, 1 (1978), 6-22.

Research in the Kiel project on language acquisition has come to the point where detailed longitudinal data are available for three acquisitional types: L1 
acquisition, naturalistic $\mathrm{L} 2$ acquisition, and foreign-language teaching. This makes it possible to check for similarities and differences between these types. The main aim here is not to reiterate such global (and obvious) differences as L1 transfer, but to investigate in more detail which acquisitional peculiarities carry over to other acquisitional types. It is shown that one such principle operative in all three acquisitional types is that free forms are acquired before bound forms.

\section{CONTRASTIVE ANAL YSIS See also abstract 79-89}

79-54 Meier, Georg F. Zur Bedeutungsdifferenzierung in slavischen Sprachen; eine onomasiologisch-konfrontative Studie am Beispiel der Bezeichnung für Extremitäten in Slavinen und Nichtslavinen. [On semantic differentiation in Slavonic languages; an onomasiological contrastive study based on names of parts of the body in Slavonic and some non-Slavonic languages.] Zeitschrift für Phonetik, Sprachwissenschaft und Kommunikationsforschung (Berlin, 30, 4 (1977), 461-73.

While the vocabulary of less advanced languages has played a part in the emergence of new nomenclatures, it has itself undergone considerable changes as a result. All human societies have the same means and possibilities of perception and cognition but perceptual and cognitive processes can be influenced by the social context. The human body is independent of social contexts and therefore 'universal', but what is not universal is the vocabulary for naming parts of the body. Examination of some Slavonic and non-Slavonic vocabularies for parts of the body shows that no language has a strictly logical or anatomical classification of meanings. The distinctions made are not clear-cut but are both synchronically and diachronically fluid. Such contrastive studies are important both for language teaching and psycholinguistics.

\section{TESTING}

79-55 Corless, Frank and others. A use of language exercise as an alternative to prose translation? Modern Languages (London), 59, 1 (1978), $1-11$.

An account of work undertaken to prepare a new test to replace the Prose in the London University Certificate of Education French examination. It was based upon a French passage in a non-literary register, which would act as a stimulus for short items testing comprehension and the ability to use specific items of syntax and lexis, and for a longer exercise (remaniement or general essay). 
[Description of the preparation work, the test itself, procedures for setting and marking it; how the test has worked in practice.] [Appendix gives sample test material.]

79-56 Gautherot, Jean-Marie. Finalités, objectifs et contrôles (examens et compositions) ou l'affiche du spectacle et comment on paye à la sortie. [Aims, objectives and assessment (examinations and essays) or the advert for the show and how you pay at the exit.] Français dans le Monde (Paris), 136 (1978), 27-31.

Governments propose aims, and researchers describe objectives and methodologies. But examination boards reverse the priorities, despise the methods and ignore social needs. Parents are disorientated and learning suffers. The real problem is unwillingness to identify needs and carry out appropriate measures (such as tape-recorded audio-comprehension and student answers). Animateurs must encourage discussion among teachers and authorities. The potential of the class itself should be exploited.

79-57 Korjakovceva, N. F. Zur Bestimmung der Niveaustufen der Lesefähigkeit in der Fremdsprache. [On determining levels of reading skill in the foreign language.] Deutsch als Fremdsprache (Leipzig), 14, 5 (1977), 280-6.

A particular skill in a foreign language can only be guided and checked if a set of objective parameters can be set up for measuring that skill. Reading is often seen not as an aim in itself but as a means of developing other skills.

A conception of foreign language reading is put forward, based on a system of three components which underlie any activity: motive, which is determined by the goal envisaged; action, or the development of a chain of operations within a definite programme; and checking, which consists in the comparison of the results achieved with the aim of the action.

After an examination of a series of psychological tests, it is concluded that the most important feature of a standard in reading is reading flexibility, which can only be achieved by a high standard of reading technique. The author develops a statistical method for measuring the standard of reading which, it is claimed, offers the possibility of developing exercises with definite aims in view. The ultimate aim is that by the end of the second year students at foreign-language institutes should be able to read foreign literature at the required level without difficulty. 
79-58 Norrish, Norma. Using the language laboratory to test linguistic performance and communicative ability. System (Linköping), 6, 1 (1978), 30-40.

An experimental year of oral testing of French using the language laboratory, carried out at Victoria University, New Zealand, is described. The language laboratory was used to administer initial grading tests, and aural comprehension and oral expression tests. For aural comprehension, the traditional dictation was replaced by dictée à trous (cloze-type exercises), and activity exercises (e.g. drawings made from instructions on tape). [Description of tapes for ' controlled oral expression', 'free expression', and free conversation; evaluation and administration.] These techniques were found to be a reasonably fair way of evaluating performance for up to 100 students at any level, though the system is still being modified and extended.

\section{LANGUAGE PLANNING}

79-59 Isaev, M.I. Решение национально языковых проблем в советскуг зпоху. [The solution of national language problems since the Revolution.] Bonpocbl языкознания (Moscow), 6(1977), $3-12$.

Lenin's policy of absolute equality of nations and of languages was determined before 1917. After the Revolution, the decisions of the 10th Congress (1921) were particularly important. The first problem was that many languages had no alphabet; furthermore the Arabic script used in central Asia was a hindrance to literacy and the Latin alphabet was introduced. Fifty languages previously without an alphabet were given one. Naturally, some mistakes were made. However, it was correct not to introduce Cyrillic immediately as internal and external enemies would have seen this as Russian imperialism and it might have been misunderstood by the national minorities. At the end of the '30s most alphabets were changed to Cyrillic. Languages were enriched by borrowings from Russian and democratised; they took on new functions, both practical and cultural. The smaller minorities became bilingual: this is especially important when the second language is Russian.

The Marxist-Leninist idea of full equality was maintained at the 22nd Congress (1961). The special role of Russian was also emphasised. Reasons for its use for communication between the nationalities of the Soviet Union are given. Its position is different from that of other international languages, for they are not second native languages but have been used for national and social oppression. Beyond the Soviet Union, Russian has a vital world role despite the efforts of anticommunists who maintain that Russian has been spread artificially and by force, especially within the Soviet Union. 


\section{COURSE DESIGN}

79-60 Bautier, R. Pratiques de communication et processus idéologiques. [Modes of communicating and ways of processing ideas.] Langue Française (Paris), 36 (1977), 93-8.

Attitudinal and situational aspects of language can be used in planning a language refresher course for adults [references]. Wider and deeper than 'techniques of expression', it concentrates on analysis rather than production, involves the participants' own comments and discusses content and form. It makes use of linguistics, logic, psychology and sociology. [Judgments of facts vs. value-judgments, evolved and restricted codes, how individuals relate to dominance discourse.]

79-61 McDonough, J. E. English for Academic Purposes: some factors in listening comprehension. EDUTEC (Mexico), 4 (undated), 31-41.

Factors relevant to course planning and materials design for listening comprehension in EAP are outlined. Listening to lectures and taking efficient notes is one 'terminal skill' in a wider matrix of academic activities. The process of understanding and committing to paper what has been understood involves perceptual and psychological, as much as linguistic, factors. Few foreign students can understand the content of a lecture sufficiently to be able to begin taking notes. The materials writer can help by equipping students with strategies which will act as stepping stones towards the required skill, by selecting valid exercise types and sequencing them along relevant parameters. [List of suitable exercise types.]

A basic distinction is made between 'localised' understanding (immediate perception of lexical items, stress, etc.) and 'global' understanding (categorisation, ordering and recall of information over longer stretches of discourse). This parallels distinctions made by psychologists when discussing primary and secondary memory. 'Global' understanding, which requires the operation of secondary memory, is most relevant to the activity under discussion. The paradox is that the teacher needs to train the student to segment and recognise at the localised level, but also needs to help him make the transition to global understanding as soon as possible. [Different aspects of global or semantic understanding are distinguished, with implications for the materials writer. References.] 
TEACHING METHODS See also abstracts 79-87, -93

79-62 Bim, I. L. Einige Tendenzen bei der Umgestaltung des Fremdsprachenunterrichts. [Some trends in the reorganisation of foreignlanguage teaching.] Fremdsprachenunterricht (Berlin), 21, 11 (1977), 510-17.

The teaching of foreign languages in the Soviet Union has changed radically in both theory and practice over the last ten years. Some of the methodological changes which have emerged in the wake of the newer theories, in particular the increased emphasis on the need for greater control over the learning process without inhibiting creative activity, are examined, together with their practical application in the school [examples], and implications for teacher training.

79-63 Brown, H. Douglas. Some limitations of C-L/CLL models of second-language teaching. TESOL Quarterly (Washington, DC), 11, 4 (1977), 365-72.

Seven years ago language teachers were introduced to a new concept of teaching a second language (L2) in the 'counselling-learning'(C-L), whole-person model of education, and more specifically, 'community language learning' (CLL). This has focused attention on the whole person, on the affective domain, and on revolutionary methods of teaching. Some of the major limitations of the model that need to be considered are: (1) Curran's particular interpretation of the role of a 'counsellor' in a counsellor-client relationship; (2) the host of affective variables (social, cultural, personality) operating within any one learner; (3) the unsuitability of CLL considering the variety of cognitive styles utilised by learners; (4) the inadequacy of relying on inductive, learner-initiated responses; and finally (5) the budgetary and curricular difficulties of carrying out a CLL approach. Special attention to these five limitations should enable language teachers to adapt and modify CLL effectively in a variety of language-teaching situations.

79-64 La Forge, Paul G. Uses of social silence in the interpersonal dynamics of community language learning. TESOL Quarterly (Washington, DC), 11, 4 (1977), 373-82.

Japanese, American, and Spanish CLL (community language learning) groups engage in foreign-language learning with a different reaction to silence. These reactions may be due to cultural or other causes, but the focus of this article is on silence as a psychodynamic phenomenon, and how teachers can use social silence to promote speaking ability. It refers to silence on the part of the teacher, students, or when called for by the CLL contract, for example, during 
reflection periods. First, affective binds connected with social silence are shown in three types of CLL group conversation experiences. Second, some CLL constructs are explained in order to show how teachers can use social silence to help their students. Third, it is argued that the use of social silence leads to the solution of affective binds and progress through the five CLL language learning stages. Teachers who are unable to use CLL should become aware of psychodynamic factors, such as social silence, in the teaching relationship. The result should be a more effective learning relationship with the students.

\section{BILINGUAL TEACHING See also abstract 79-51}

79-65 Harley, Birgit and Swain, Merrill. An analysis of the verb system used by young learners of French. Interlanguage Studies Bulletin (Utrecht), 3, 1 (1978), 35-79.

The early French immersion classroom provides a setting for second-language learning which resembles a natural language-acquisition setting in some important respects. But communicative needs largely determine what French is acquired, hence the focus is likely to be on aspects which convey cognitive, ideational, meaning. This study concentrates on a detailed analysis of the verb system in children from a grade five French immersion class in a Toronto school, as compared with control groups.

The findings indicate several ways in which the immersion pupils differ from comparison groups: they operate with simpler and less redundant verb systems, mastering the most generalised forms. In the area of verb syntax, they opt for a simpler pattern approximating to their mother tongue rather than to French. In vocabulary, however (an extremely important area for realising meaning), they are close to the comparison groups. These differences are clearly connected with setting in which the immersion children find themselves. Once they can make themselves understood in class, there is no strong social incentive to develop further.

79-66 Swain, Merrill. French immersion: early, late or partial? Canadian Modern Language Review (Toronto), 34, 3 (1978), 577-85.

Three possible formats for a bilingual education programme are described. Each programme aims to develop a high degree of proficiency in second-language (French) skills while at the same time maintaining a level of proficiency in first-language (English) skills and achievement in academic content consistent with that of peers in unilingual English educational programmes. The question is, whether each programme achieves these goals equally well. At the theoretical level, the comparison of results amongst the three programmes provides - 
albeit somewhat indirectly - supportive evidence for the threshold hypothesis, which states that learners must attain a certain 'threshold' level in their second language if they are to profit from instruction in that language. Partial immersion students have probably not attained this level. At the practical level, it is certainly less expensive and involves less disruption of an educational system to introduce educational change at a later grade level. [Summary of the evaluations made during the Bilingual Education Project at the Ontario Institute for Studies in Education, for early total French immersion, early partial French immersion, and late partial French immersion.] [References.]

79-67 Vladés Fallis, Guadalupe. A comprehensive approach to the teaching of Spanish to bilingual Spanish-speaking students. Modern Language Journal (St Louis, Mo), 62, 3 (1978), 102-10.

Spanish teachers in the United States need to define the teaching of the native language for bilingual Spanish-speaking students. Two types of programme for teaching the standard dialect are here contrasted: (1) the 'limited normative approach', in which the standard dialect is mainly the subject rather than the medium of instruction, and the aim is to extirpate non-standard features from the student's dialect; and (2) the 'comprehensive language development programme', which uses the standard dialect as the medium of instruction in developing all the skills, and stresses that certain regional features are universally acceptable. The two-year programme aims to develop strong functional skills in the Spanish language: spelling, reading, composition, grammar, and familiarity with standard spoken Spanish. [References.]

\section{CLASS METHODS See also abstracts 79-70/1, -77/8, -81, $-84 / 5$}

79-68 Walter, Heribert. Unterrichtspraktische Gesichtspunkte zur Durchführung einer fremdsprachlichen Debatte. [Practical teaching perspectives on conducting a debate in a foreign language.] Die Neueren Sprachen (Frankfurt am Main), 27, 1 (1978), 32-51.

The formal debate, although popular in English schools, is rarely used as a method of teaching foreign languages. It can be a useful oral exercise in that its competitive element leads to an increase in pupil motivation and to the development of team spirit in addition to linguistic competence.

The different types of debate are examined and the possibilities and problems of using debate in the teaching of a foreign language, particularly French, are discussed in detail. The need for thorough preparation and follow-up is stressed. 


\section{PRONUNCIATION}

79-69 Gatbonton, Elizabeth. Patterned phonetic variability in secondlanguage speech: a gradual diffusion model. Canadian Modern Language Review (Toronto), 34, 3 (1978), 335-47.

A study is reported exploring the relationship between observed variability in second-language data and the process in which correct variants are acquired and incorrect ones replaced. In particular, three phonological variables in the English speech of French Canadian second-language speakers in Montreal, Quebec, were investigated to find out whether the occurrence of correct and incorrect variants in their speech at any one stage is predictable and whether the systematicity or randomness of the data is related to the acquisition and replacement of correct and incorrect variants.

The findings support the view that phonetic variability in second-language speech is patterned, not random, and that the source of this variability and systematicity is the process by which the learner masters new elements of the target language. The model may be useful in determining how materials should be sequenced to meet the needs of students. [References.]

79-70 Trocmé, Hélène. L'éducation de la perception sensorimotrice: un pré-requis de l'apprentissage de la langue. [Education of sensory-motor perception: a pre-requisite of language learning.] IUT Bulletin Pédagogique (Nancy), 53 (1978), 11-22.

To hear the target language effectively, beginners must overcome the blunting of their receptor senses; and develop an unselfconscious state of total auditory alertness. The programme suggested involves: listening to breathing; rhythmic exercises; listening to silence punctuated by music, whispers and voices; exploring the duration of sounds and boundaries of vocal registers, the colour, warmth and coldness, timbre and intensity of voices; wordless intonation sequences; percussion rhythms. In early comprehension lessons, pupils should be inspired to do something about relating to other people, instead of simply soaking up facts.

\section{VOCABULARY TEACHING}

79-71 Judd, Elliott L. Vocabulary teaching and TESOL: a need for re-evaluation of existing assumptions. TESOL Quarterly (Washington, DC), 12, 1 (1978), 71-6.

Vocabulary instruction in TESOL has been relegated to secondary status in favour of an emphasis on the teaching of syntactic structures. Vocabulary 
acquisition has been seen as a means to improve reading and listening comprehension and not as a skill vital in its own right. These views are inappropriate for ESL programmes at the university level. Massive vocabulary instruction should begin as soon as possible and the status of lexical knowledge should be given greater emphasis. Relevant lexical items within the student's syntactic knowledge should be selected and immediately integrated into the classroom setting. Repetition of vocabulary items in a natural linguistic context will aid the students in dealing with multiple meanings and the sociolinguistic contexts of words and phrases.

79-72 Saragi, T. and others. Vocabulary learning and reading. System (Linköping, Sweden), 6, 2 (1978), 72-8.

Because different learners have followed different courses and because they do not all learn the same vocabulary from the same course, material for vocabulary learning needs to be individualised. The experiment reported here shows that extensive reading results in a substantial amount of vocabulary learning. Vocabulary teaching exercises can be individualised to avoid wasting learners' time [example].

\section{LANGUAGE FOR SPECIAL PURPOSES See abstracts $79-61,-92,-106$}

READING See also abstracts $79-22,-57,-61,-72$

79-73 Cziko, Gary A. Differences in first- and second-language reading: the use of syntactic, semantic and discourse constraints. Canadian Modern Language Review (Toronto), 34, 3 (1978), 473-89.

The psycholinguistic theory of reading emphasises the importance of the reader's use of contextual information, rather than that of the visual information on the printed page. The contextual information available to the reader is of three types - syntactic, semantic and discourse constraints. Two studies are reported which aimed to isolate, analyse and directly compare the use of these constraints by readers of French (either as a first or second language). [Method; results.]

The results of these two studies suggest that syntactic, semantic and discourse constraints serve as important sources of information for the fluent first-language reader and that much of the difficulty in reading a second language may be due to the inability of the second-language reader to make full use of these contextual constraints. These studies also give evidence for a 
developmental order in the ability of the second-language reader to use contextual constraints. It appears that sensitivity to syntactic constraints develops before sensitivity to both semantic and discourse constraints. [Appendix gives materials used in the studies; references.]

79-74 Doctorow, Marleen and others. Generative processes in reading comprehension. Joumal of Educational Psychology (Washington, DC), 70, 2 (1978), 109-18.

In the generative model of learning with understanding, reading comprehension occurs when readers actively construct meaning for text. In two experiments with a total of 488 sixth graders, where time to learn was held constant across all treatments, it was predicted and found that the facilitation of generative processes by the insertion of paragraph headings and instructions to generate sentences about story paragraphs during encoding produced the greatest comprehension, followed in turn by instructions to generate sentences, the insertion of paragraph headings, and then by reading the same stories without generative instructions or paragraph headings. The combination of inserted paragraph headings and instructions to generate sentences about paragraphs approximately doubled comprehension and recall in each experiment.

79-75 Thomson, Michael. A psycholinguistic analysis of reading errors made by dyslexics and normal readers. Journal of Research in Reading (Leeds), 1, 1 (1978), 7-20.

The reading errors made by a group of dyslexic children and a control group with above average reading attainment were analysed using Goodman's Taxonomy of Oral Miscues (Goodman, 1969). The criteria for selection of the 'dyslexic' group are described, and the children were given the Neale Analysis of Reading Ability (Neale, 1958) from which errors were noted. On the Neale Analysis categories, only omissions distinguished between the two groups; on Goodman's taxonomy the dyxlexic children made more errors at the level of graphic and phonemic analysis rather than at a semantic or syntactical level; the control group made more errors at bound morpheme, phrase and sentence level. It was concluded that the dyslexics showed some different types of error, at the perceptual rather than linguistic level, and did not make errors similar to beginning readers. 
79-76 Zaefferer, Dietmar. Understanding misunderstanding: a proposal for an explanation of reading choices. Joumal of Pragmatics (The Hague), 1, 4 (1977), 329-46.

This paper discusses the notion of misunderstanding and proposes a detailed classification of different types. Then it develops, with the aid of decision analysis, a general framework for the explanation of those choices in the process of interpretation which are left open by the grammar. A sample misunderstanding is presented and informally discussed, and a proposal is made as to how to supplement the grammar of speech acts in order to represent the data adequately. Finally, an explanation of the sample case is given in terms of decision analysis, and possible ways of generalising the suggested explanatory scheme are outlined.

COMMUNICATION See also abstracts $79-58,-68,-85,-88$

79-77 Folomkina, S. K. Einige Aspekte der Entwicklung der mündlichen Sprachausübung. [Some aspects of the development of oral linguistic competence.] Fremdsprachenunterricht (Berlin), 21, 11 (1977), 525-30.

Three aspects of the development of oral linguistic skills are considered: the selection of appropriate lexical and grammatical material, methods of facilitating the acquisition and retention of this material by the student and the problem of how to encourage the use of language in spontaneous communication within the classroom.

The selection of linguistic material is usually based on certain generally recognised criteria such as frequency of occurrence. The criterion of thematic value leads to vocabulary having to be learnt which will be of little use in a real situation. Language teaching should begin from the selection of situations which are likely to occur frequently, followed by an examination of the linguistic material used in those situations. Methods of tuition relying on the mechanical repetition of structures and vocabulary do not enable students to develop a mastery of language in spontaneous situations and should be replaced by methods allowing more freedom of communication. The methods generally employed to encourage the use of language in the classroom (e.g. Nacherzählung) are highly artificial. However, traditional methods can be adapted to stimulate spontaneous and creative expression arising from the students' own experience and ideas [examples]. 
79-78 Kimball, Margot C. and Palmer, Adrian S. The dialogue game: a prototypical activity for providing proper intake in formal instruction. TESOL Quarterly (Washington, DC), 12, 1 (1978), 17-29.

The interpretation of implicit meaning ('proper intake') is an important but frequently neglected component of classroom language teaching when the goal is informal communication. One technique for providing it is the dialogue game, a form of communication game, presented here as a prototype which can be adapted for any content area and for students at any level. [Examples of two kinds of variables which the writer of such games can manipulate to tailor the game to students' needs; sample games of different types; observations from experience of using games in the classroom.]

79-79 Littlewood, William T. Oral communication ability. Modem Languages (London), 59, 1 (1978), 28-33.

The article focuses on the following five domains of communicative skill: (1) estimation and exploitation of shared knowledge; (2) choice or interpretation of register; (3) knowledge of form/function relationships; (4) categorisation of meanings; (5) verbalisation. Language teaching has traditionally regarded the last of these domains (and to a lesser extent, the fourth) as its field of activity. The other three are important components of the ability to communicate, and merit greater attention. In some cases, this attention will consist largely of remaining aware of what skills pupils must learn to perform, and providing appropriate instruction and practice. In other cases, more basic investigation of specific languages is needed, in order to discover precisely what repertoire their native speakers possess, and what guides their choice from it in specific situations. In this way, language teaching may be helped to progress beyond the teaching of structure, towards the wider goal of developing communicative competence.

79-80 Taylor, Barry P. and Wolfson, Nessa. Breaking down the free conversation myth. TESOL Quarterly (Washington, DC), 12, 1 (1978), 31-9.

An approach called 'directed conversation' is advocated in place of free or unfocused conversation. This approach combines aspects of dramatic play-acting with a functional approach toward the teaching of socio-linguistic speech behaviour for specific types of real-world encounters. This technique forces students to learn not only the vocabulary and expressions necessary for one restricted type of situation, but also capitalises on well established cognitive abilities to analogise and generalise into parallel social and linguistic situations, thereby facilitating the acquisition of both linguistic and sociolinguistic rules. 


\section{WRITING}

79-81 Boyd, J. A. Evaluating the active communication skills: writing. Canadian Modern Language Review (Toronto), 34, 4 (1978), 735-45.

A method is outlined for structuring the teaching and testing programme to allow the student to progress systematically (and therefore confidently) through a number of stages, from copying to free composition: (1) copying, (2) developing sentences from a visual stimulus other than the printed word, (3) by manipulating the printed word, (4) from a visual stimulus by means of word completions, and (5) from an oral stimulus. The formula for marking will vary with the developmental level of the writing skill [examples].

\section{AUDIO-VISUAL AIDS See also abstract 79-91}

79-82 Messora, Noemi and Sherill, Barbara. A new 'role' for audiovisual aids: a slide-sequence of strategies and protocols. System (Linköping, Sweden), 6, 2 (1978), 79-88.

The use of roles in language teaching, based on research into the use of language codes in specific social situations, can, with the aid of slide-programme and language lab, reduce both the stress involved in learning and the time required in memorising. [The nine stages of the slide-tape approach are described with examples - they move from an introduction to a particular situation, through exahanges of protocols (e.g. request-granting, requestrefusal), to freer interaction.]

VISUAL AIDS See abstract 79-84

LANGUAGE LABORATORIES See abstract 79-58, -82

\section{ADULTS See also abstract 79-60}

79-83 Coste, Daniel. Analyse des besoins et enseignement des langues étrangères aux adultes. [Analyses of needs and the teaching of foreign languages to adults.] Études de Linguistique Appliquée (Paris), 27 (1977), 51-77.

Research since 1970 into the language needs of adult learners and its effects on, and relation to, language teaching is reviewed and discussed. Most research in this field has been into language needs and language skills in employment, since 
there appears to be a gulf between what schools and universities teach and what commerce and industry require; employing organisations have financed surveys which tend to reflect the language needs of employers rather than of learners.

The concept of need is difficult to define. Research into needs is no guarantee of good teaching nor should it be allowed to determine either the content or the objectives of courses. However, although the signs are that the adult learner is better served and receives more appropriate teaching than the school population has done in the past, there remains a certain confusion between ends and means; more thought is required concerning the purpose and function of research into language neeeds. [Diagrams; references.]

\section{DRAMA See also abstract 79-82}

79-84 Goethals, Michaël. Creative and cognitive foreign-language learning. ITL (Louvain), 36 (1977), 3-44.

The theoretical background is given for experiments with role play in a cognitive foreign-language learning strategy, as a learning activity - rather than as an activity for diagnosis - in the guided-open stage. Video-taped experiments in secondary schools have been set up in Louvain. The problems, the possibilities, the choice made and the ways of coding and exploiting the video material are discussed.

79-85 Scarcella, Robin C. Socio-drama for social interaction. TESOL Quarterly (Washington, DC), 12, 1 (1978), 41-6.

Socio-drama (a type of role-playing) can be used effectively to develop communication skills. First, by participating in several enactments, students produce new sentences based on their own behaviour or the spontaneous constructions produced by other students. Second, as in real life communication, socio-drama obliges students to restructure their language use according to the social context. Third, socio-drama promotes social-interaction, a prerequisite for communication.

Socio-drama has high student appeal. Its game structure allows students to try out new behaviours without fear of social penalty. It also encourages students to repair communication lapses occurring in both their own and in others' speech. This in turn enables the teacher to diagnose communication breakdowns for future lessons. Socio-drama creates a comfortable atmosphere which promotes cross-cultural understanding. 
ENGLISH See also abstracts 79-23, $-61,-63,-69,-71,-80,-85$

79-86 Cook, Walter A. Semantic structure of the English modals. TESOL Quarterly (Washington, DC), 12, 1 (1978), 5-15.

The recognition and proper use of the meanings underlying the English modal verbs are a problem for the student of English as a foreign language even in relatively advanced stages. The problem lies not in the surface positioning of the modals nor in their wide range of meanings, but in associating the right modal with the right meaning. Current research in generative semantics attempts to express the logical structures underlying English sentences in terms of a central verb and the nouns which accompany it. Tense, negation and modality are added to the structure as higher predicates. These structures reveal differences in the modals.

Research on the semantic structure of the modals is relevant for the teacher of English in determining the content to be taught. The teacher can decide what is the best method for communicating what is known about the structure of the language.

79-87 Klimentenko, A. D. Експериментальное обучение английскому языку детей с шести лет в школе. [An experiment in the teaching of English to six-year old schoolchildren.] Иностранные языки в школе (Moscow), 2 (1978), 37-47.

An account is given of an experiment in the teaching of English to six-year olds. It was conducted in three phases between 1972 and 1976, the first of which consisted of controlled experiments with group size and instruction periods (length and frequency). It was found that 35 -minute periods were preferable to 20-minute periods, but that class size was not an important factor, given the chosen methods of instruction which included considerable use of choral exercises. Acquisition of the material was good, except that the number of lexical items acquired was smaller than anticipated. However, considerable difficulty was experienced when the transition to reading was attempted two years later. The second phase of the experiment sought to maximise what was satisfactory in the first. At the end children had acquired a larger vocabulary and were able to vary their own speech (which was not the case in the first phase), but at the expense of a noticeable increase in grammatical mistakes. It was established that the problem of developing monologue speech is maturational in the sense that children had the same difficulties in the domain of the mother tongue. The acquisition of reading was greatly improved by the introduction of reading after the first term of the first year, using methods based on the work of Doman and Decrolie. The final phase is a variant based on the experience of the first two phases and gives promising results. It is argued that children 
starting a foreign language at six can learn quickly thanks to their powers of memory and mimicry and other physiological factors, thereby reducing the number of hours required for language learning higher up the school.

FRENCH See also abstracts $79-55 / 6,-58,-60,-65 / 6,-68,-73$

79-88 Bonin, Thérèse $M$. The role of colloquial French in communication and implications for language instruction. Modern Language Journal (St Louis, Mo), 62, 3 (1978), 90-102.

The extent to which listening comprehension is impaired when students are confronted with the colloquial, as opposed to formal, use of French, was investigated in a study of 128 trainee French teachers. [Methods; results.] The results revealed a very low level of comprehension of colloquial French and a huge discrepancy between comprehension of colloquial and of formal French. Spontaneous speech (combining all linguistic aspects) presents most difficulty, and the single most difficult aspect of colloquial French is its lexicon. There was a general lack of awareness of the relationship between speech styles and social situations. [Possible remedies in training teachers in listening comprehension using authentic materials are outlined, and class methods suggested.] The socio-cultural parameters of colloquial French are discussed, and its chief linguistic features are presented. [References.]

\section{GERMAN}

79-89 Ponten, Jan-Peter. Vom Nutzen einer theoretisch abgesicherten kontrastiven Grammatik für die Stellung des Faches Deutsch als Fremdsprache. [On the usefulness of a theoretically sound contrastive grammar for the status of German as a foreign language.] Deutsch als Fremdsprache (Leipzig), 14, 4 (1977), 194-7.

The status of German as a foreign language has declined. An optimal approach to teaching is therefore needed if German is to be taught to as high a level as possible in the time available and maintain its rightful place in the school curriculum. An optimal organisation of the learning process can best be carried out on the basis of a contrastive analysis of the source language and German which includes a contrastive grammar. This presupposes intensive research in comparative linguistics. 
79-90 Schuhmacher, Helmut. Einsprachige Wörterhiicher für Studenten. [Monolingual dictionaries for students.] Deutsche Sprache (Munich), 1 (1978), 59-78.

Various types of monolingual German dictionary are compared in the light of their relevance to the non-German student or teacher of German. The comparison points out the strengths and weaknesses of available German dictionaries. Dictionaries which attempt to provide a basic vocabulary stumble on the problem of the lack of any systematic principles for the selection of vocabulary. They often give relatively few verbs and offer little explanation of usage. They are inadequate for the advanced student. General one-volume dictionaries cover too wide a field and are designed primarily for the German native speaker rather than the foreigner. Even the multi-volume dictionaries do not always give adequate semantic distinctions or explanation of usage for the foreigner. Synonym dictionaries often assume a prior knowledge of the meaning of a word. It is concluded that dictionaries aimed specifically at the advanced student of German are few and those which are available have serious shortcomings [examples].

\section{SPANISH See also abstract 79-67}

79-91 Duvivier, Roger. Musz der Sprachunterricht umkehren? Le cas favorable du SGAV en espagnol. [The global-structural and audiovisual approach to Spanish: a success story?] Revue des Langues Vivantes (Brussels), 43, 3 (1977), 298-314.

Spanish occupies the position of third or fourth foreign language taught in Belgian schools. Criticisms of the state of modern-language teaching in secondary schools are examined as they apply to the teaching of Spanish. The Spanish audio-visual courses and materials available are discussed. Hispanists have been able to benefit from the experience of teachers of Germanic languages and have also derived advantage from the basic similarities between Romance languages. In spite of difficulties and problems, the audio-visual approach to the teaching of Spanish must be judged to have succeeded.

79-92 Ezquerra, Raimundo. El vocabulario general de orientación científica y sus estratos. [General scientific vocabulary and its levels.] Revista Española de Lingǘstica (Madrid), 7, 2 (1977), 178-89.

A commentary on the work by García Hoz bearing the same title. The statistical base of the work is criticised. Its aim of establishing the general vocabulary of intellectual inquiry at pre-university level is approved. [Des- 
cription of the work. Comparison with CREDIF, Vocabulaire général d'orientation scientifique (1971).]

79-93 Yalden, Janice. A comparison of achievement in four intermediate courses in Spanish. System (Linköping, Sweden), 6, 2 (1978), 89-97.

An attempt was made in the study reported here to measure the relative achievement of students enrolled in four different types of intermediate-level colledge courses in Spanish, including one of near-immersion design. The enquiry was first carried out in 1973 then replicated in 1974. [Method; results.]

The hypothesis that students on intensive courses would have somewhat lower scores was confirmed. But the similarity of scores in all skills between four disparate courses suggests that there is an integrative ability in language learning which leads to a fairly even development of language abilities, no matter what skills are emphasised in a given course of study. Discrete-point testing failed to separate the skills neatly, as they overlapped considerably. 